\title{
Testosterone as a protective factor against atherosclerosis - immunomodulation and influence upon plaque development and stability
}

\author{
C J Malkin, P J Pugh, R D Jones ${ }^{1}$, T H Jones ${ }^{1,2}$ and K S Channer \\ Department of Cardiology, Royal Hallamshire Hospital, Sheffield S10 2JF, UK \\ ${ }^{1}$ Academic Unit of Endocrinology, Division of Genomic Medicine, University of Sheffield Medical School S10 2RX, UK \\ ${ }^{2}$ Centre for Diabetes and Endocrinology, Barnsley District General Hospital, Barnsley \\ (Requests for offprints should be addressed to K S Channer, M131, Cardiology, Royal Hallamshire Hospital, Glossop Road. Sheffield S10 2JF, UK; Email: \\ Kevin.Channer@sth.nhs.uk)
}

\begin{abstract}
Inflammation plays a central pathogenic role in the initiation and progression of coronary atheroma and its clinical consequences. Cytokines are the mediators of cellular inflammation and promote local inflammation in the arterial wall, which may lead to vascular smooth muscle apoptosis, degradation of the fibrin cap and plaque rupture. Platelet adhesion and thrombus formation then occur, resulting clinically in unstable angina or myocardial infarction. Recent studies have suggested that cytokines are pathogenic, contributing directly to the disease process. 'Anti-cytokine' therapy may, therefore, be of benefit in preventing or slowing the progression of cardiovascular disease. Both oestrogens and testosterone have been shown to have immune-modulating effects; testosterone in par-
\end{abstract}

ticular appears to suppress activation of pro-inflammatory cytokines. Men with low testosterone levels are at increased risk of coronary artery disease. An antiinflammatory effect of normal physiological levels of sex hormones may, therefore, be important in atheroprotection. In this article, we discuss some of the mechanisms involved in atherosclerotic coronary artery disease and the putative link between testosterone deficiency and atheroma formation. We present the hypothesis that the immune-modulating properties of testosterone may be important in inhibiting atheroma formation and progression to acute coronary syndrome.

Journal of Endocrinology (2003) 178, 373-380

\section{Cytokines in coronary artery disease}

It has become clear in recent years that the clinical events of the acute coronary syndromes in patients with coronary artery disease (CAD) result from a change from quiescent atheroma to ruptured plaque in which inflammation within the vessel wall is intimately associated (Libby et al. 2002). Patients with CAD have elevated circulating levels of cytokines and C-reactive protein (CRP) (Ikonomidis et al. 1999), with higher levels present in those with unstable angina or acute myocardial infarction (Manten et al. 1998). The CRP level, a marker of cytokine activation, is not only a strong independent predictor of mortality and subsequent events in patients admitted to hospital with an acute infarct (Tommasi et al. 1999) but is the best predictor of clinically significant atherosclerotic disease in unselected 'healthy' populations (Ridker et al. 1997). It was previously thought that the degree of coronary artery narrowing was the main predictor of subsequent events, but angiographic studies have shown that most infarcts occur in vessels with stenoses of less than $70 \%$ (Falk et al. 1995). Thus, the clinical manifestations of coronary atheroma are not directly related to the local burden of atheroma but to the amount of plaque inflammation. Moreover, statins reduce plasma lipid levels and coronary events and alter plaque constituents but have only a minimal effect on the degree of stenosis (Jukema et al. 1995). It would appear, therefore, that it is the quality and not the quantity of plaque which is most important.

The initial process of atheroma formation involves accumulation of cholesterol in the arterial wall and expression of adhesion molecules and chemokines by endothelial cells, in particular monocyte chemoattractant protein-1 (MCP-1) (Reckless et al. 1999). As a consequence, monocytes and macrophages infiltrate the vessel wall and produce inflammatory cytokines including tumour 
Table 1 Actions of tumour necrosis factor

In vitro

Impaired endothelial nitric oxide synthase production Increased inducible nitric oxide synthase production Impaired vasodilation

Reduced myocyte contractility

Increased metalloproteinase activity

Reduced TIMP activity

Promotes apoptosis

Induces expression of IL-1 $\beta$, IL-6, MCP-1

In vivo

Impaired left ventricular function

Left ventricular dilation

Heart failure

Impaired peripheral vasodilation

Protein breakdown

Impaired collagen synthesis

TIMP, tissue inhibitor of matrix metalloproteinase; IL, interleukin; MCP, monocyte chemoattractant protein.

necrosis factor (TNF) (Tipping \& Hancock 1993), a central mediator of disease (see Table 1). These factors, along with oxidised low-density-lipoprotein (LDL) cholesterol promote further MCP-1 expression and amplify the production of cytokines by macrophages and endothelial cells (Terkeltaub et al. 1998, Krishnaswamy et al. 1999) (Fig. 1).

Within the plaque, a lipid core is separated from the lumen by a fibrin cap. Smooth muscle cells migrate into the plaque and produce collagen and elastin to bolster the cap and extracellular matrix. The stability of the fibrin cap is affected by continuing inflammation; $\mathrm{T}$ lymphocytes within the lesion secrete $\gamma$-interferon, which reduces synthesis of connective tissue and inhibits smooth muscle cell proliferation, serving to weaken the cap (Warner et al. 1989). Activated macrophages produce matrix metalloproteinases (MMPs) such as collagenases and gelatinases. These enzymes digest and break down plaque matrix and are closely regulated: TNF and interleukin (IL)- $1 \beta$ promote their release while anti-inflammatory cytokines such as IL-4 and IL-10 reduce MMP activity (Saren et al. 1996, George 1998). The balance of stimulatory and inhibitory cytokines is crucial to the stability of the plaque. Degradation of the fibrin cap may lead to erosion with consequent breach of endothelium and exposure of collagen or to the catastrophic breakdown of the plaque, 'plaque rupture', with release of the lipid core and tissue factor. Plaque erosion and rupture are responsible for most acute coronary syndromes. Myocardial infarction is caused by thrombosis in the coronary artery as a complication of plaque breakdown in $90 \%$ of occasions. Despite recent advances in treatment, the case fatality rate for myocardial infarction is still high with about $50 \%$ of patients dying (Tunstall-Pedoe et al. 1999). Long-term survivors in the absence of cardiac failure have a better prognosis but still have an average $3 \%$ annual risk of a vascular event, in most cases because of complications from atherosclerotic plaque (Haq et al. 1995).
The stability of the fibrous cap may be threatened when the rate of extracellular matrix breakdown exceeds the rate of synthesis. This may occur as a consequence of excess cytokine-induced production of MMPs or due to increased rate of vascular smooth muscle cell apoptosis. Rupture of the fibrous cap most often occurs where the layer of vascular smooth muscle cells is thinnest, highlighting their importance (Davies \& Thomas 1985). The relative rates of vascular smooth muscle cell proliferation and apoptosis are critical in governing plaque stability (Fig. 2). Vascular smooth muscle cells taken from plaques show higher rates of apoptosis (Geng \& Libby 1995), have senescent morphology (Orekhov et al. 1984) and are more sensitive to apoptotic stimuli than smooth muscle cells from normal vascular tissue (Bennett et al. 1995). The common areas of plaque rupture - the shoulders of the plaque - have the highest density of apoptotic vascular smooth muscle cells. Once again, inflammatory cells and their cytokines are the key. Macrophages can directly induce vascular smooth muscle cell apoptosis (Boyle et al. 2001), as can TNF, IL-1 $\beta$ and interferon- $\gamma$ (Geng et al. 1996).

\section{Testosterone and coronary artery disease}

Men are more than twice as likely as women to die from coronary heart disease, and this ratio is consistent in all populations and is not related to differences in risk factors (British Heart Foundation Statistics Database 1998). Sex hormones decline with age in both sexes but the relationship of sex hormones to cardiovascular risk is complex. Pre-menopausal women have a lower incidence of CAD, but this rises after menopause so that the risk rapidly approaches that of males. One explanation for this phenomenon is that sex hormones influence the development and progression of coronary artery disease. In males the increasing incidence of CAD with age is associated with a decline in testosterone levels. A similar, more pronounced epidemiological pattern occurs in women after the menopause, so that there is a catch-up time of around 10 years. The presumed protective effects of oestrogens in women have been widely investigated with a series of large observational studies tending to support this notion (Gordon et al. 1978, Stampfer et al. 1991). However, randomised control trials designed to assess the effect of female hormone replacement on cardiovascular events have reported either no benefit (Hulley et al. 1998) or harm (Rossouw et al. 2002). The explanation for these seemingly opposing results is unclear. The positive observational data have been attributed to 'compliance bias' whereby women on hormone replacement therapy (HRT) tend to be healthier, from a higher socio-economic class and exhibit fewer cardiovascular risk factors (Petitti 1998). The negative trial data of HRT in women with established vascular disease (HERS) (Hulley et al. 1998) 


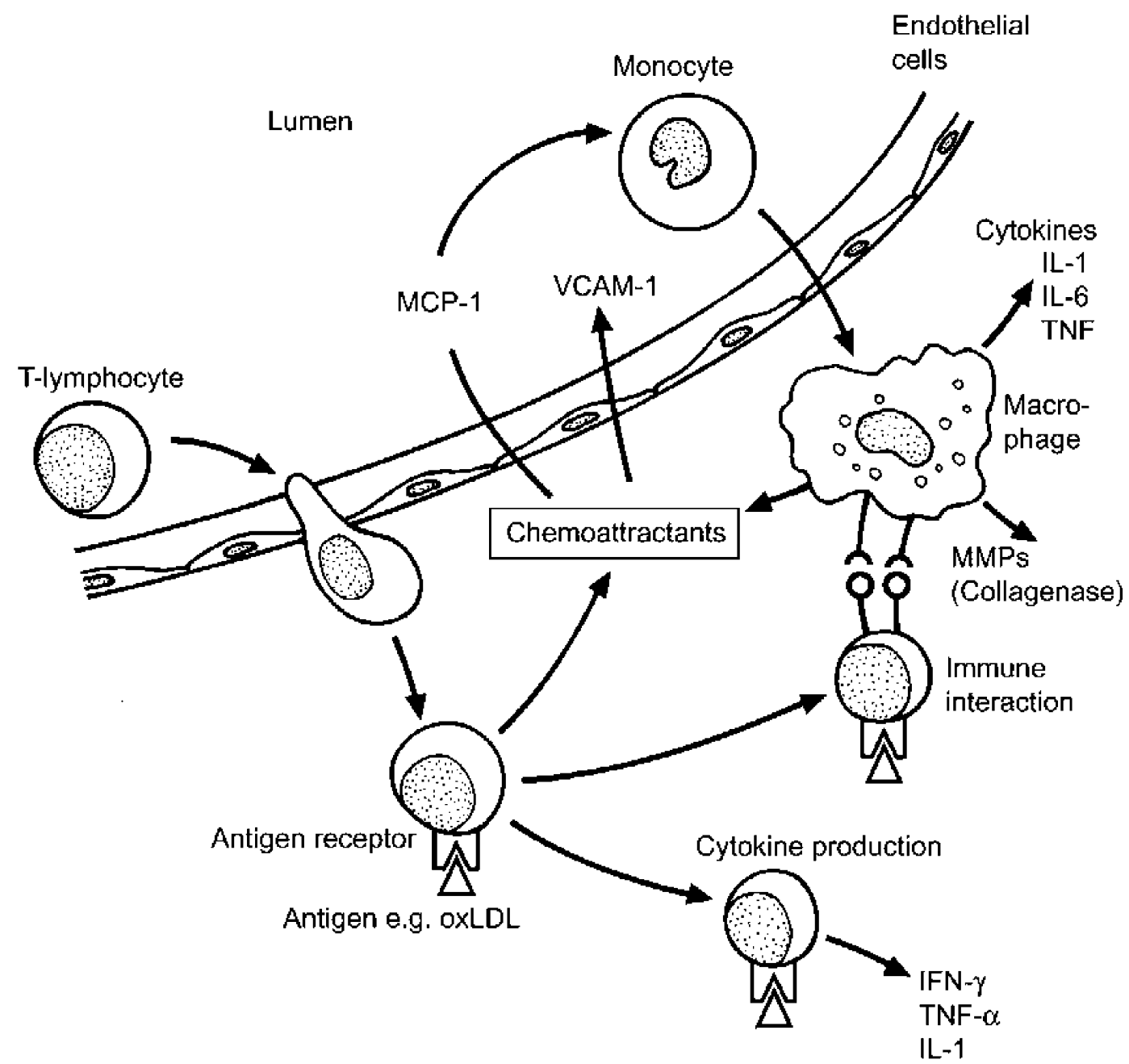

Figure 1 Immune and inflammatory reaction. T lymphocytes and monocytes are drawn to the plaque and pass through the endothelium. T-cells interact with antigens and other immune cells producing proinflammatory cytokines. Monocytes mature into macrophages producing cytokines and collagenases. There is self-perpetuation with the production of chemoattractants such as MCP-1 and expression of adhesion molecules such as vascular cell adhesion molecule-1 (VCAM-1). IFN, interferon; oxLDL, oxidised LDL; MMPs, matrix metalloproteinase enzymes.

has been attributed to the higher use of statins in the control group (Pan \& Boal 1999) and to late randomisation of subjects (with consequent failure to prove a late trend to cardio-protection) (Ong et al. 1999). The Women's Health Initiative study (Rossouw et al. 2002) in unselected 'healthy' women also found no benefit and indeed small absolute increases in the risk of vascular disease and cancer. This trial has also been criticised for the high age of the study population, with $50 \%$ over 65 years old and thus high prevalence of sub-clinical vascular disease (Radford \& Church 2002). Both trials have been criticised for the relatively high doses of hormones used and particularly the synthetic progestin, medoxyprogesterone, since this hormone can inhibit the beneficial effects of oestrogen (Pearson Murphy 2002). These recent randomised control trials are disappointing and surprising, but it should be noted that hormone replacement therapy does not replicate the same physiology as seen in the pre-menopausal woman. Although female HRT cannot currently be recommended to reduce CAD risk it may well be that different hormone preparations and delivery in a younger population will have some efficacy.

In comparison, the role of androgens in CAD has been relatively neglected, although a detrimental effect is usually presumed. However, we have found that low rather than high testosterone levels are associated with CAD (English et al. 2000a) and that low serum testosterone is associated with increased aortic atheroma (Hak et al. 2002). Furthermore, low testosterone levels are associated with several risk factors for the development of CAD, 


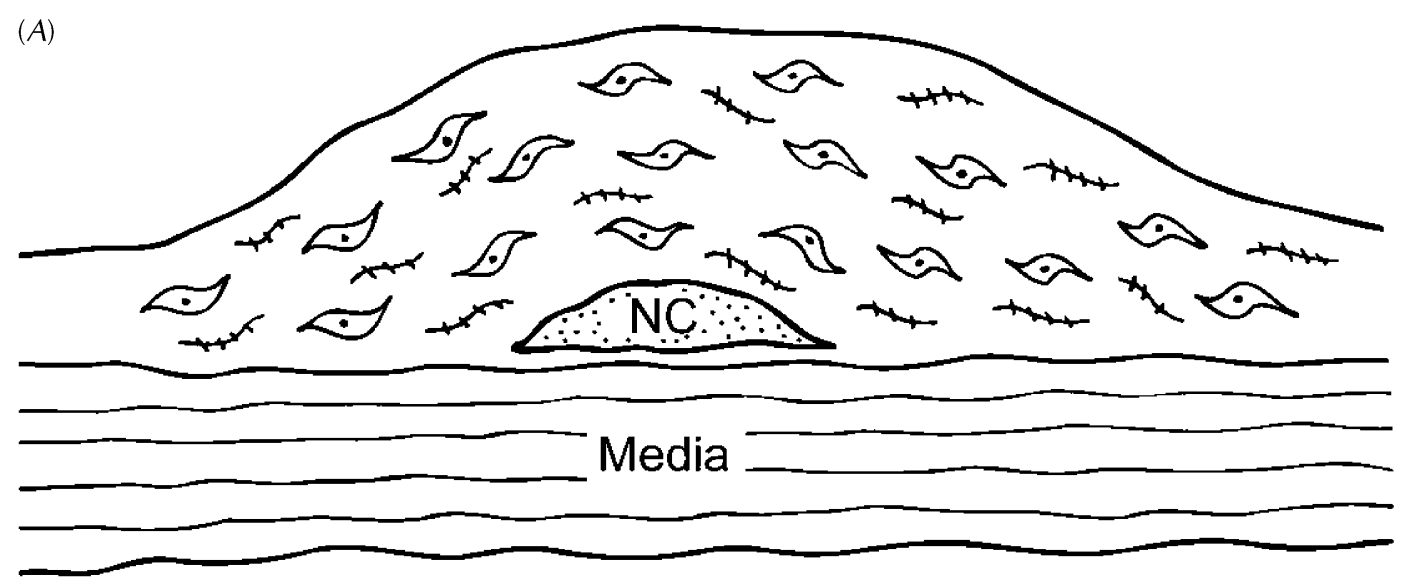

(B)

\section{Macrophages producing cytokines e.g. TNF, IL1 and MMPs e.g. collagenase}

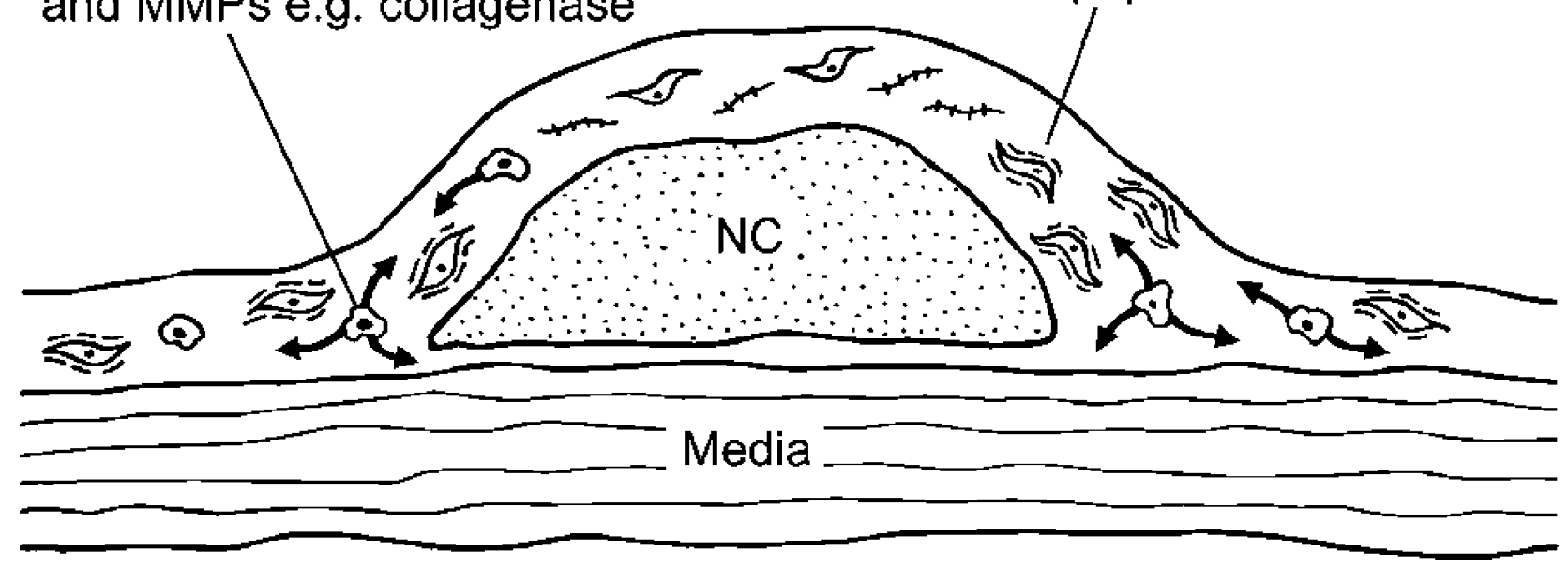

Figure 2 (A) Stable plaque characterised by small necrotic core (NC), abundant vascular smooth muscle cells, and a dense thick plaque cap with extensive collagen/elastin fibres. (B) Unstable plaque characterised by a larger necrotic core, thin plaque cap with sparse smooth muscle cells and collagen fibres, inflammatory cells producing cytokines and MMPs and apoptic/senescent smooth muscle cells.

including systolic and diastolic hypertension, adverse lipid profile and high levels of fibrinogen, insulin and procoagulable factors (reviewed in English et al. 1997).

Despite this, it has yet to be established that low testosterone level is an independent risk factor for the development of CAD in man; it may simply be an epiphenomenon. There is, however, experimental evidence that androgens have a disease-modifying role in atheroma formation. Several male animal studies have shown that androgens reduce diet- and injury-induced atherosclerosis. These studies have their limitations, as most use the cholesterol-fed rabbit with or without induced endothelial injury. This is a well-established model but has some differences compared with native human atheroma. The cholesterol diet creates a hyperlipidaemia characterised by high very low-densitylipoprotein (VLDL) rather than a high LDL more commonly seen in humans and the lipid deposition seen is in the form of cholesterol ester-enriched fatty streaks rather than mature plaque (Arad et al. 1989). However fatty streaks are known precursors of mature plaque and the morphology and behaviour of cells in the vessels of animal model fatty streaks mimics that seen in human atheroma (Gordon et al. 1988). The results are tabulated in Table 2. All but one study has shown a beneficial or neutral effect of androgen therapy on the formation and progression of atherosclerosis. The only negative study, by Toda et al. (1984), used a dose of testosterone at $150 \mathrm{mg}$ per day, 
Table 2 Effects of androgen on atherosclerosis in males

\section{Model}

\section{Reference}

Toda et al. (1984)

Gordon et al. (1988)

Arad et al. (1989)

Larsen et al. (1993)

Eich et al. (1993)

Bruck et al. (1997)

Alexandersen et al. (1999)

Hanke et al. (2001) 7-day-old chicks

Cholesterol-fed rabbits, aortic

balloon-injury

Cholesterol-fed rabbits

Cholesterol-fed rabbits, castrated

Cholesterol-fed rabbits, heterotopic heart transplanted

Cholesterol-fed rabbits, castrated

Cholesterol-fed rabbits, castrated

or sham-operated

Endothelium-denuded rabbit aorta
Intervention

T 150 mg daily

T 30 mg daily

DHEA

DHEA

T 25 mg twice weekly

DHEA

T $25 \mathrm{mg} / \mathrm{kg} /$ week

Castration

$\mathrm{T}$

DHEA

Incubation with $\mathrm{T}$
Outcome

$\uparrow$ lipid accumulation in aorta

$\leftrightarrow$ no changes

$\downarrow$ plaque size

$\downarrow$ fatty streak formation

Trend to lower cholesterol content of aorta

$\downarrow$ number of significantly stenosed vessels

$\downarrow$ plaque size

$\uparrow$ aortic atherosclerosis

$\downarrow \downarrow$ aortic atherosclerosis

$\downarrow$ aortic atherosclerosis

$\downarrow$ plaque size

T, testosterone; DHEA, dehydroepiandrosterone.

which is a very high dose and caused increases in fatty accumulation in the aorta (as well as delayed maturation of external phenotype) whereas a lower $30 \mathrm{mg}$ dose showed no increase in fatty accumulation. The other studies use doses of hormones that create levels either within the physiological range or modestly supra-physiological. The study of Alexandersen et al. (1999) is the most elegant model. Here, castration of male animals without hormone replacement induced a 100\% increase in aortic atheroma compared with sham-operated animals. Testosterone replacement to a high physiological range with intramuscular injections or tablets inhibited this response. The final amount of aortic atheroma was less in the intramuscular testosterone group than in the sham-operated group. The reason for this is not certain but the final fasting testosterone level in the intramuscular testosterone group was significantly higher than in the sham-operated group, suggesting a dose-response effect. Although these animal models have clear limitations, the overwhelming impression is that the androgens dehydroepiandrosterone and testosterone in high physiological doses inhibit experimental atheroma.

\section{Testosterone and cytokines - a possible mechanism of protection}

The means by which testosterone may confer benefit in $\mathrm{CAD}$ is not clear. We have previously demonstrated that 3 months of physiological testosterone treatment leads to symptomatic improvement in men with angina (English et al. 2000b). The acute and chronic anti-ischaemic properties of testosterone have been reported by other groups (Jaffe 1977, Rosano et al. 1999) and this effect is most likely mediated by coronary artery vasodilatation (Webb et al. 1999), which appears to involve calcium channel antagonism in a gender-specific fashion (English et al. 2001, 2002). However, we propose that testosterone may also have a role in limiting the vascular inflammation and cytokine activity underpinning the pathophysiology of atherosclerosis. Macrophages, lymphocytes and vascular smooth muscle cells (VSMC) all possess androgen receptors (Fujimoto et al. 1994, Benten et al. 1999a,b). In addition, there is evidence of a biofeedback loop since cytokines appear to impair synthesis and release of testosterone (Mealy et al. 1990). There have been no studies directly examining the action of androgens on cytokine production in patients with CAD. However, there is evidence from several studies that androgens possess immune-modulating properties. In the majority of these reports, androgens, including testosterone, have been shown to suppress the activity of pro-inflammatory cytokines while enhancing that of anti-inflammatory factors (see Table 3). In a recent study, hypogonadal men were found to have a greater degree of inflammatory activation compared with healthy controls, including higher serum cytokine levels (Yesilova et al. 2000). Androgen therapy in these patients led to a reduction in circulating cytokines. Clearly these studies only provide circumstantial evidence of an anti-cytokine effect of testosterone and further studies are needed. It is of interest that testosterone has been used with some success to treat males with autoimmune rheumatic conditions (Bizzarro et al. 1987, Cutolo et al. 1991). Although the studies do not report levels of serum cytokines, these diseases are essentially cytokine mediated and clinical improvement would be expected to be associated with reduced expression of pro-inflammatory cytokines.

In addition to direct anti-inflammatory actions, testosterone also appears to have an important effect on rates of vascular smooth muscle cell proliferation and apoptosis, an important factor in maintaining plaque integrity (Newby \& Zaltsman 1999). The anabolic actions of testosterone in increasing protein synthesis and skeletal muscle cell size via 
Table 3 Effects of androgens on cytokines

Androgen

Model

\section{Reference}

Chao et al. (1995)

D'Agostino et al. (1999)

$\mathrm{T}$

$\mathrm{T}$

Kanda et al. (1996)

Kanda et al. (1997)

T

$T$

Li et al. (1993)

Gornstein et al. (1999)

Hofbauer et al. (1999)

Hatakeyama et al. (2002)

Araneo et al. (1991)

Dalal et al. (1997)

Kimura et al. (1998)

Ben-Nathan et al. (1999)

Padgett \& Loria (1998)

Straub et al. (1998)

Spinedi et al. (1992)
T

$\mathrm{T}$

$\mathrm{T}$

$\mathrm{T}$

DHT

DHT

DHEA

DHEA

DHEA

DHEA

Castration
Rat macrophage

Mouse marophage

Human monocytes

Human monocytes (patients with systemic lupus

erythematosus)

Human monocytes (patients with rheumatoid arthritis

and healthy subjects)

Human gingival fibroblasts

Human osteoblasts

Human aortic endothelium

Mouse cells

Mice with auto-immune disease*

Obese rats*

Mice*

Mouse macrophages

Human monocytes

Mice*
Effect

Trend to $\downarrow$ TNF production

$\downarrow$ LPS-induced TNF

$\uparrow$ LPS-induced IL-10

$\downarrow$ IL-6 production

$\downarrow$ IL-6 production

$\downarrow$ IL-1 production

$\downarrow$ IL-6 production

$\downarrow$ IL-6 production

$\downarrow$ TNF induced VCAM- 1 and NFK $\beta$

$\downarrow \gamma$-interferon, IL-4

$\downarrow \gamma$-interferon, $\uparrow$ IL-10

$\downarrow$ TNF

$\downarrow$ IL-1, $\downarrow$ LPS-induced TNF

$\downarrow$ LPS-induced TNF, IL-1, IL-6

$\downarrow$ IL-6 production

$\uparrow$ LPS-induced TNF

*in vivo. LPS, lipopolysaccharide; T, testosterone; DHT, dihydrotestosterone; DHEA, dehydroepiandrosterone; VCAM-1, vascular cell adhesion molecule 1; IL,

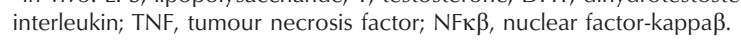

nuclear transcription are well documented. Testosterone has been shown to reverse castration-induced skeletal muscle apoptosis in rats (Boissonneault 2001) and inhibit human neuronal apoptosis (Hammond et al. 2001). Importantly, it has also been shown to enhance proliferation of human vascular smooth muscle cells (Williams et al. 2002). Testosterone could, therefore, potentially be involved in maintaining the fibrous cap of the atherosclerotic plaque by promoting smooth muscle cell stability.

\section{Conclusion}

Cytokine activation and vascular smooth muscle cell apoptosis play an integral part in the development of CAD and in the pathophysiology of acute coronary syndromes. Experimental studies show that androgens protect against the development of atheroma. Separately, androgens have been shown to suppress pro-inflammatory cytokine activity, inhibit apoptosis and enhance vascular smooth muscle cell proliferation. These actions may be responsible for their athero-protective effects. To test this hypothesis, further studies are needed, including clinical trials, to examine this mechanism and the role of androgens in cardiovascular disease.

\section{References}

Alexandersen P, Haarbo J, Byrjalsen I, Lawaetz H \& Christiansen C 1999 Natural androgens inhibit male atherosclerosis: a study in castrated, cholesterol-fed rabbits. Circulation Research 84 813-819.
Arad Y, Badimon JJ, Badimon L, Hembree WC \& Ginsberg HN 1989 Dehydroepiandrosterone feeding prevents aortic fatty streak formation and cholesterol accumulation in cholesterol-fed rabbit. Arteriosclerosis 9 159-166.

Araneo BA, Dowell T, Diegel M \& Daynes RA 1991 Dihydrotestosterone exerts a depressive influence on the production of interleukin-4 (IL-4), IL-5, and gamma-interferon, but not IL-2 by activated murine T cells. Blood 688-699.

Ben-Nathan D, Padgett DA \& Loria RM 1999 Androstenediol and dehydroepiandrosterone protect mice against lethal bacterial infections and lipopolysaccharide toxicity. Journal of Medical Microbiology 48 425-431.

Bennett MR, Evan GI \& Schwartz SM 1995 Apoptosis of human vascular smooth muscle cells derived from normal vessels and coronary atherosclerotic plaques. Journal of Clinical Investigation 95 2266-2274.

Benten, WP, Lieberherr M, Giese G, Wrehlke C, Stamm O, Sekeris CE, Mossmann H \& Wunderlich F 1999a Functional testosterone receptors in plasma membranes of $\mathrm{T}$ cells. FASEB Journal 13 123-133.

Benten WP, Lieberherr M, Stamm O, Wrehlke C, Guo Z \& Wunderlich F 1999 b Testosterone signaling through internalizable surface receptors in androgen receptor-free macrophages. Molecular Biology of the Cell 10 3113-3123.

Bizzarro A, Valentini G, Di Martino G, DaPonte A, De Bellis A \& Iacono G 1987 Influence of testosterone therapy on clinical and immunological features of autoimmune diseases associated with Klinefelter's syndrome. Journal of Clinical Endocrinology and Metabolism 64 32-36.

Boissonneault G 2001 Evidence of apoptosis in the castration-induced atrophy of the rat levator ani muscle. Endocrine Research 27 317-328.

Boyle JJ, Bowyer DE, Weissberg PL \& Bennett MR 2001 Human blood-derived macrophages induce apoptosis in human plaquederived vascular smooth muscle cells by Fas-ligand/Fas interactions. Arteriosclerosis, Thrombosis, and Vascular Biology 21 1402-1407.

British Heart Foundation Statistics Database 1998, pp 21-22. British Heart Foundation.

Bruck B, Brehme U, Gugel N, Hanke S, Finking G, Lutz C, Benda N, Schmahl FW, Haasis R \& Hanke H 1997 
Gender-specific differences in the effects of testosterone and estrogen on the development of atherosclerosis in rabbits. Arteriosclerosis, Thrombosis, and Vascular Biology 17 2192-2199.

Chao TC, Van Alten PJ, Greager JA \& Walter RJ 1995 Steroid sex hormones regulate the release of tumor necrosis factor by macrophages. Cell Immunology 160 43-49.

Cutolo M, Balleari E, Giusti M, Intra E \& Accardo S 1991 Androgen replacement therapy in male patients with rheumatoid arthritis. Arthritis and Rheumatism 34 1-5.

D’Agostino P, Milano S, Barbera C, Di Bella G, La Rosa M, Ferlazzo V, Farruggio R, Miceli DM, Miele M, Castagnetta L \& Cillari E 1999 Sex hormones modulate inflammatory mediators produced by macrophages. Annals of the New York Acadamy of Sciences $\mathbf{8 7 6}$ 426-429.

Dalal M, Kim S \& Voskuhl RR 1997 Testosterone therapy ameliorates experimental autoimmune encephalomyelitis and induces a $\mathrm{T}$ helper 2 bias in the autoantigen-specific $\mathrm{T}$ lymphocyte response. Journal of Immunology 159 3-6.

Davies MJ \& Thomas AC 1985 Plaque fissuring - the cause of acute myocardial infarction, sudden ischaemic death, and crescendo angina. British Heart Journal 53 363-373.

Eich DM, Nestler JE, Johnson DE, Dworkin GH, Ko D, Wechsler AS \& Hess ML 1993 Inhibition of accelerated coronary atherosclerosis with dehydroepiandrosterone in the heterotopic rabbit model of cardiac transplantation. Circulation 87 261-269.

English KM, Steeds R, Jones TH \& Channer KS 1997 Testosterone and coronary heart disease: is there a link? Quarterly Journal of Medicine 90 787-791.

English KM, Mandour O, Steeds RP, Diver MJ, Jones TH \& Channer KS 2000a Men with coronary artery disease have lower levels of androgens than men with normal coronary angiograms. European Heart Journal 21 890-894.

English KM, Steeds RP, Jones TH, Diver MJ \& Channer KS $2000 b$ Low-dose transdermal testosterone therapy improves angina threshold in men with chronic stable angina: a randomized, double-blind, placebo-controlled study. Circulation 102 1906-1911.

English KM, Jones RD, Jones TH, Morice AH \& Channer KS 2001 Gender differences in the vasomotor effects of different steroid hormones in rat pulmonary and coronary arteries. Hormone Metabolism Research 33 645-652.

English KM, Jones RD, Jones TH, Morice AH \& Channer KS 2002 Testosterone acts as a coronary vasodilator by a calcium antagonistic action. Journal of Endocrinological Investigation 25 455-458.

Falk E, Shah PK \& Fuster V 1995 Coronary plaque disruption. Circulation 92 657-671.

Fujimoto R, Morimoto I, Morita E, Sugimoto H, Ito Y \& Eto S 1994 Androgen receptors, 5 alpha-reductase activity and androgendependent proliferation of vascular smooth muscle cells. Journal of Steroid Biochemistry and Molecular Biology 50 169-174.

Geng YJ \& Libby P 1995 Evidence for apoptosis in advanced human atheroma. Colocalization with interleukin-1 beta-converting enzyme. American Journal of Pathology 147 251-266.

Geng YJ, Wu Q, Muszynski M, Hansson GK \& Libby P 1996 Apoptosis of vascular smooth muscle cells induced by in vitro stimulation with interferon-gamma, tumor necrosis factor-alpha, and interleukin-1 beta. Arteriosclerosis, Thrombosis, and Vascular Biology 16 $19-27$.

George SJ 1998 Tissue inhibitors of metalloproteinases and metalloproteinases in atherosclerosis. Current Opinion in Lipidology 9 413-423.

Gordon GB, Bush DE \& Weisman HF 1988 Reduction of atherosclerosis by administration of dehydroepiandrosterone. A study in the hypercholesterolemic New Zealand white rabbit with aortic intimal injury. Journal of Clinical Investigation 82 712-720.

Gordon T, Kannel WB, Hjortland MC \& McNamara PM 1978 Menopause and coronary heart disease. The Framingham Study. Annals of Internal Medicine 89 157-161.
Gornstein RA, Lapp CA, Bustos-Valdes SM \& Zamorano P 1999 Androgens modulate interleukin- 6 production by gingival fibroblasts in vitro. Journal of Periodontology 70 604-609.

Hak AE, Witteman JC, de Jong FH, Geerlings MI, Hofman A \& Pols HA 2002 Low levels of endogenous androgens increase the risk of atherosclerosis in elderly men: the Rotterdam study. Journal of Clinical Endocrinology and Metabolism 87 3632-3639.

Hammond J, Le Q, Goodyer C, Gelfand M, Trifiro M \& LeBlanc A 2001 Testosterone-mediated neuroprotection through the androgen receptor in human primary neurons. Journal of Neurochemistry $\mathbf{7 7}$ $1319-1326$.

Hanke H, Lenz C, Hess B, Spindler KD \& Weidemann W 2001 Effect of testosterone on plaque development and androgen receptor expression in the arterial vessel wall. Circulation 103 1382-1385.

Haq IU, Jackson PR, Yeo WW \& Ramsay LE 1995 Sheffield risk and treatment table for cholesterol lowering for primary prevention of coronary heart disease. Lancet 346 1467-1471.

Hatakeyama H, Nishizawa M, Nakagawa A, Nakano S, Kigoshi T \& Uchida K 2002 Testosterone inhibits tumor necrosis factor-alphainduced vascular cell adhesion molecule- 1 expression in human aortic endothelial cells. FEBS 530 129-132.

Hofbauer LC, Ten RM \& Khosla S 1999 The anti-androgen hydroxyflutamide and androgens inhibit interleukin- 6 production by an androgen-responsive human osteoblastic cell line. Journal of Bone Mineral Research 14 1330-1337.

Hulley S, Grady D, Bush T, Furberg C, Herrington D, Riggs B \& Vittinghoff E 1998 Randomized trial of estrogen plus progestin for secondary prevention of coronary heart disease in postmenopausal women. Heart and Estrogen/progestin Replacement Study (HERS) Research Group. JAMA 280 605-613.

Ikonomidis I, Andreotti F, Economou E, Stefanadis C, Toutouzas P \& Nihoyannopoulos P 1999 Increased proinflammatory cytokines in patients with chronic stable angina and their reduction by aspirin. Circulation 100 793-798.

Jaffe MD 1977 Effect of testosterone cypionate on postexercise ST segment depression. British Heart Journal 39 1217-1222.

Jukema JW, Bruschke AV, van Boven AJ, Reiber JH, Bal ET, Zwinderman AH, Jansen H, Boerma GJ, van Rappard FM, Lie KI et al 1995 Effects of lipid lowering by pravastatin on progression and regression of coronary artery disease in symptomatic men with normal to moderately elevated serum cholesterol levels. The Regression Growth Evaluation Statin Study (REGRESS). Circulation 91 2528-2540.

Kanda N, Tsuchida T \& Tamaki K 1996 Testosterone inhibits immunoglobulin production by human peripheral blood mononuclear cells. Clinical and Experimental Immunology 106 410-415.

Kanda N, Tsuchida T \& Tamaki K 1997 Testosterone suppresses anti-DNA antibody production in peripheral blood mononuclear cells from patients with systemic lupus erythematosus. Arthritis and Rheumatism 40 1703-1711.

Kimura M, Tanaka S, Yamada Y, Kiuchi Y, Yamakawa T \& Sekihara H 1998 Dehydroepiandrosterone decreases serum tumor necrosis factor-alpha and restores insulin sensitivity: independent effect from secondary weight reduction in genetically obese Zucker fatty rats. Endocrinology 139 3249-3253.

Krishnaswamy G, Kelley J, Yerra L, Smith JK \& Chi DS 1999 Human endothelium as a source of multifunctional cytokines: molecular regulation and possible role in human disease. Journal of Interferon Cytokine Research 19 91-104.

Larsen BA, Nordestgaard BG, Stender S \& Kjeldsen K 1993 Effect of testosterone on atherogenesis in cholesterol-fed rabbits with similar plasma cholesterol levels. Atherosclerosis 99 79-86.

Li ZG, Danis VA \& Brooks PM 1993 Effect of gonadal steroids on the production of IL-1 and IL-6 by blood mononuclear cells in vitro. Clinical and Experimental Rheumatology 11 157-162.

Libby P, Ridker PM \& Maseri A 2002 Inflammation and atherosclerosis. Circulation 105 1135-1143. 
Manten A, de Winter RJ, Minnema MC, ten Cate H, Lijmer JG, Adams R, Peters RJ \& van Deventer SJ 1998 Procoagulant and proinflammatory activity in acute coronary syndromes. Cardiovascular Research 40 389-395.

Mealy K, Robinson B, Millette CF, Majzoub J \& Wilmore DW 1990 The testicular effects of tumor necrosis factor. Annals of Surgery 211 470-475.

Newby AC \& Zaltsman AB 1999 Fibrous cap formation or destruction - the critical importance of vascular smooth muscle cell proliferation, migration and matrix formation. Cardiovascular Research 41 345-360.

Ong PJ, Sorensen MB, Hayward CS, Webb CM \& Collins P 1999 Hormone replacement therapy for secondary prevention of coronary heart disease. JAMA 281 794-795 [author reply 796-797].

Orekhov AN, Karpova II, Tertov VV, Rudchenko SA, Andreeva ER, Krushinsky AV \& Smirnov VN 1984 Cellular composition of atherosclerotic and uninvolved human aortic subendothelial intima. Light-microscopic study of dissociated aortic cells. American Journal of Pathology 115 17-24.

Padgett DA \& Loria RM 1998 Endocrine regulation of murine macrophage function: effects of dehydroepiandrosterone, androstenediol, and androstenetriol. Journal of Neuroimmunology 84 $61-68$.

Pan CX \& Boal J 1999 Hormone replacement therapy for secondary prevention of coronary heart disease. JAMA 281794 [author reply 796-797].

Pearson-Murphy BE 2002 Risks of postmenopausal hormone replacement. JAMA 2882820 [author reply 2823-2824].

Petitti DB 1998 Hormone replacement therapy and heart disease prevention: experimentation trumps observation. JAMA 280 $650-652$.

Radford N \& Church T 2002 Risks of postmenopausal hormone replacement. JAMA 2882819 [author reply 2823-2824].

Reckless J, Rubin EM, Verstuyft JB, Metcalfe JC \& Grainger DJ 1999 Monocyte chemoattractant protein-1 but not tumor necrosis factor-alpha is correlated with monocyte infiltration in mouse lipid lesions. Circulation 99 2310-2316.

Ridker PM, Cushman M, Stampfer MJ, Tracy RP \& Hennekens CH 1997 Inflammation, aspirin, and the risk of cardiovascular disease in apparently healthy men. New England Journal of Medicine $\mathbf{3 3 6}$ 973-979.

Rosano GM, Leonardo F, Pagnotta P, Pelliccia F, Panina G, Cerquetani E, della Monica PL, Bonfigli B, Volpe M \& Chierchia SL 1999 Acute anti-ischemic effect of testosterone in men with coronary artery disease. Circulation 99 1666-1670.

Rossouw JE, Anderson GL, Prentice RL, LaCroix AZ, Kooperberg C, Stefanick ML, Jackson RD, Beresford SA, Howard BV, Johnson KC et al. 2002 Risks and benefits of estrogen plus progestin in healthy postmenopausal women: principal results from the Women's Health Initiative randomized controlled trial. JAMA 288 321-333.

Saren P, Welgus HG \& Kovanen PT 1996 TNF-alpha and IL-1 beta selectively induce expression of $92-\mathrm{kDa}$ gelatinase by human macrophages. Journal of Immunology 157 4159-4165.

Spinedi E, Suescun MO, Hadid R, Daneva T \& Gaillard RC 1992 Effects of gonadectomy and sex hormone therapy on the endotoxin-stimulated hypothalamo-pituitary-adrenal axis: evidence for a neuroendocrine-immunological sexual dimorphism. Endocrinology 131 2430-2436.

Stampfer MJ, Colditz GA, Willett WC, Manson JE, Rosner B, Speizer FE \& Hennekens CH 1991 Postmenopausal estrogen therapy and cardiovascular disease. Ten-year follow-up from the nurses' health study. New England Journal of Medicine 325 756-762.

Straub RH, Konecna L, Hrach S, Rothe G, Kreutz M, Scholmerich J, Falk W \& Lang B 1998 Serum dehydroepiandrosterone (DHEA) and DHEA sulfate are negatively correlated with serum interleukin-6 (IL-6), and DHEA inhibits IL-6 secretion from mononuclear cells in man in vitro: possible link between endocrinosenescence and immunosenescence. Journal of Clinical Endocrinology and Metabolism 83 2012-2017.

Terkeltaub R, Boisvert WA \& Curtiss LK 1998 Chemokines and atherosclerosis. Current Opinion in Lipidology 9 397-405.

Tipping PG \& Hancock WW 1993 Production of tumor necrosis factor and interleukin-1 by macrophages from human atheromatous plaques. American Journal of Pathology 142 1721-1728.

Toda T, Toda Y, Cho BH \& Kummerow FA 1984 Ultrastructural changes in the comb and aorta of chicks fed excess testosterone. Atherosclerosis $\mathbf{5 1} 47-57$.

Tommasi S, Carluccio E, Bentivoglio M, Buccolieri M, Mariotti M, Politano M \& Corea L 1999 C-reactive protein as a marker for cardiac ischemic events in the year after a first, uncomplicated myocardial infarction. American Journal of Cardiology $\mathbf{8 3}$ 1595-1599.

Tunstall-Pedoe H, Kuulasmaa K, Mahonen M, Tolonen H, Ruokokoski E \& Amouyel P 1999 Contribution of trends in survival and coronary-event rates to changes in coronary heart disease mortality: 10-year results from 37 WHO MONICA project populations. Monitoring trends and determinants in cardiovascular disease. Lancet 353 1547-1557.

Warner SJ, Friedman GB \& Libby P 1989 Immune interferon inhibits proliferation and induces 2'-5'-oligoadenylate synthetase gene expression in human vascular smooth muscle cells. Journal of Clinical Investigation 83 1174-1182.

Webb CM, McNeill JG, Hayward CS, de Zeigler D \& Collins P 1999 Effects of testosterone on coronary vasomotor regulation in men with coronary heart disease. Circulation 100 1690-1696.

Williams MR, Ling S, Dawood T, Hashimura K, Dai A, Li H, Liu JP, Funder JW, Sudhir K \& Komesaroff PA 2002

Dehydroepiandrosterone inhibits human vascular smooth muscle cell proliferation independent of ARs and ERs. Journal of Clinical Endocrinology and Metabolism 87 176-181.

Yesilova Z, Ozata M, Kocar IH, Turan M, Pekel A, Sengul A \& Ozdemir IC 2000 The effects of gonadotropin treatment on the immunological features of male patients with idiopathic hypogonadotropic hypogonadism. Journal of Clinical Endocrinology and Metabolism 85 66-70.

Received in final form 29 April 2003

Accepted 14 May 2003 